\title{
Assessment of Palliative Care in Lung Cancer in Turkey
}

\author{
Y. Bülbül ${ }^{1} \quad$ T. Ozlu ${ }^{1} \quad$ S. Arinc ${ }^{17} \quad$ B.A. Ozyurek ${ }^{18} \quad$ H. Gunbatar ${ }^{2} \quad$ A. Senturk ${ }^{21} \quad$ A. Bahadir ${ }^{19}$

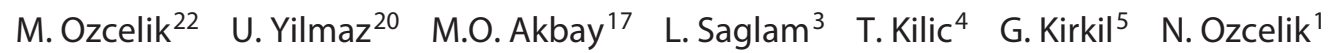

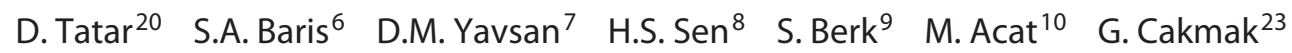

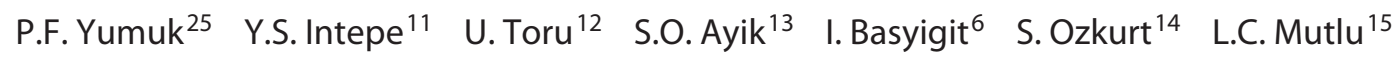 \\ Z.A. Yasar ${ }^{16}$ H. Esme ${ }^{24}$ M.M. Erol ${ }^{26}$ O. Oruc ${ }^{17} \quad$ Y. Erdoğan ${ }^{18} \quad$ S. Asker ${ }^{2} \quad$ A. Ulas ${ }^{21} \quad$ S. Erol $^{20}$

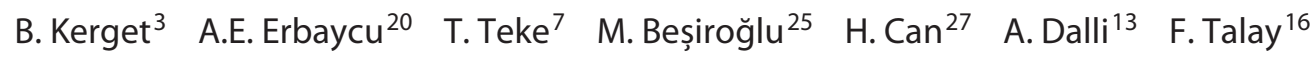 \\ Department of Chest Diseases, School of Medicine, ${ }^{1}$ Karadeniz Technical University, Trabzon, ${ }^{2}$ Yuzuncu Yil \\ University, Van, ${ }^{3}$ Ataturk University, Erzurum, ${ }^{4}$ Inonu University, Malatya, ${ }^{5}$ Firat University, Elazıg, ${ }^{6}$ Kocaeli \\ University, Kocaeli, ${ }^{7}$ Necmettin Erbakan University, Konya, ${ }^{8}$ Dicle University, Diyarbakir, ${ }^{9}$ Cumhuriyet University, \\ Sivas, ${ }^{10}$ Karabük University, Karabük, ${ }^{11}$ Bozok University, Yozgat, ${ }^{12}$ Dumlupinar University, Kutahya, ${ }^{13}$ Katip \\ Celebi University, Izmir, ${ }^{14}$ Pamukkale University, Denizli, ${ }^{15}$ Namik Kemal University, Tekirdag, ${ }^{16}$ Abant Izzet Baysal \\ University, Bolu, Pulmonary Diseases and Thoracic Surgery Education and Research Hospitals of ${ }^{17}$ Sureyyapasa, \\ Istanbul, ${ }^{18}$ Ataturk, Ankara, ${ }^{19}$ Yedikule, Istanbul, and ${ }^{20}$ Dr. Suat Seren, Izmir, Education and Research Hospitals of \\ ${ }^{21}$ Ataturk, Ankara, ${ }^{22}$ Kartal, Istanbul, ${ }^{23}$ Haseki, Istanbul, and ${ }^{24}$ Konya, Konya, ${ }^{25}$ Department of Medical Oncology \\ School of Medicine, Marmara University, Istanbul, ${ }^{26}$ Department of Thoracic Surgery School of Medicine, Uludag \\ University, Bursa, and ${ }^{27}$ Department of Family Medicine School of Medicine, Katip Celebi University, Izmir, Turkey
}

\section{Keywords}

Lung cancer · Palliation · Palliative treatment · Symptoms · Treatment

\begin{abstract}
Objective: To investigate the symptoms of lung cancer in Turkey and to evaluate approaches to alleviate these symptoms. Subjects and Methods: This study included 1,245 lung cancer patients from 26 centers in Turkey. Demographic characteristics as well as information regarding the disease and treatments were obtained from medical records and patient interviews. Symptoms were evaluated using the Edmonton Symptom Assessment Scale (ESAS) and were graded on a scale between 0 and 10 points. Data were compared using the $\mathrm{X}^{2}$, Student $t$, and Mann-Whitney $\mathrm{U}$ tests. Potential predictors of symptoms were analyzed using logistic regres-
\end{abstract}

\section{KARGER}

E-Mail karger@karger.com www.karger.com/mpp
(C) 2016 S. Karger AG, Basel

Karger
Open access

This is an Open Access article licensed under the terms of the Creative Commons Attribution-NonCommercial 3.0 Unported license (CC BY-NC) (www.karger.com/OA-license), applicable to the online version of the article only. Distribution permitted for non-commercial purposes only. sion analysis. Results: The most common symptom was tiredness ( $n=1,002 ; 82.1 \%$ ), followed by dyspnea $(n=845$; $69.3 \%)$, appetite loss ( $n=801 ; 65.7 \%)$, pain ( $n=798 ; 65.4 \%)$, drowsiness ( $n=742 ; 60.8 \%)$, anxiety ( $n=704 ; 57.7 \%)$, depression ( $n=623 ; 51.1 \%$ ), and nausea ( $n=557 ; 45.5 \%)$. Of the 1,245 patients, 590 (48.4\%) had difficulty in initiating or maintaining sleep. The symptoms were more severe in stages III and IV. Logistic regression analysis indicated a clear association between demographic characteristics and symptom distress, as well as between symptom distress (except nausea) and well-being. Overall, 804 (65.4\%) patients used analgesics, 630 (51.5\%) received treatment for dyspnea, 242 (19.8\%) used enteral/parenteral nutrition, 132 (10.8\%) used appetite stimulants, and 129 (10.6\%) used anxiolytics/antidepressants. Of the 799 patients who received analgesics, $173(21.7 \%)$ reported that their symptoms were under control, and also those on other various treatment modalities
Prof. Yılmaz Bülbül

Department of Chest Diseases, School of Medicine, Karadeniz Technical University Farabi Cd. No: 66

TR-61080 Trabzon (Turkey)

E-Mail bulbulyilmaz@yahoo.com 
(dyspnea: 78/627 [12.4\%], appetite stimulant: 25/132 [18.9\%], and anxiolytics/antidepressants: $25 / 129$ [19.4\%]) reported that their symptoms were controlled. Conclusion: In this study, the symptoms progressed and became more severe in the advanced stages of lung cancer, and palliative treatment was insufficient in most of the patients in Turkey.

(c) 2016 S. Karger AG, Basel

\section{Introduction}

Lung cancer is a highly mortal disease with poor survival rates. Patients with lung cancer suffer many limitations due to symptoms related to the disease and its treatment [1]. Most patients with lung cancer are symptomatic at presentation, and most of them experience multiple symptoms, including dyspnea, pain, fatigue, anorexia, nausea, anxiety, and depression, especially in the advanced stages [1].

Lung cancer symptoms are known to cause secondary effects on the emotional, social, physical, and spiritual well-being of patients [2]. Because there is a close relationship between the symptoms, quality of life, and survival, early implementation of palliative care has been reported to improve a patient's quality of life, symptom burden, and even survival [3]. However, in clinical practice, the importance of symptoms and palliative care is often neglected by physicians, and is generally not considered in the disease's management [4].

The goal of palliative care is to provide relief from pain and other distressing symptoms in order to give patients and their families the best possible quality of life, regardless of disease stage or need for other therapies [5]. Common pulmonary symptoms of lung cancer that require palliative therapy include those caused by the cancer itself, i.e., dyspnea, wheezing, cough, hemoptysis, and chest pain; locoregional metastases within the thorax, i.e., superior vena cava syndrome, pleural effusions, etc.; or by distant metastases, i.e., bone and brain [1]. Hence, this study, which was conducted in Turkey, aimed to investigate the symptoms of lung cancer and its treatment, as well as to evaluate approaches for palliating those symptoms.

\section{Subjects and Methods}

Following approval from the Ethics Committee of Karadeniz Technical University Faculty of Medicine, this multicenter and prospective study was performed at 26 centers in Turkey from March 2014 to September 2014. During the study period, all lung
Table 1. Characteristics of disease and treatment options in patients with lung cancer

$n(\%)$

Histopathologic diagnosis $(n=1,245)$

Squamous cell carcinoma

$489(39.3)$

Adenocarcinoma

$369(29.6)$

Small-cell lung carcinoma

$237(19.0)$

NSCLC-not otherwise specified

$127(10.2)$

Others

$23(1.8)$

Stage of disease $(n=1,202)$

Stage I

Stage II

$78(6.5)$

Stage III

$121(10.1)$

$332(27.6)$

Stage IV

$671(55.8)$

Metastases

Bones $(n=663) \quad 291(43.9)$

Brain $(n=667) \quad 154(23.1)$

Liver $(n=665) \quad 134(20.2)$

Adrenal glands $(n=664) \quad 116(17.5)$

Other $(n=718) \quad 151(20.0)$

Treatment options ${ }^{1}(n=1,159)$

Chemotherapy

$532(45.9)$

Chemo-radiotherapy

$327(28.2)$

Surgery

$213(18.4)$

Radiotherapy

$87(7.5)$

${ }^{1}$ First-line treatment options that have been delivered or are currently being delivered.

cancer patients (both old and newly diagnosed for any stage) who presented at the hospital were included in the study if they agreed to participate and signed informed consent.

Demographic characteristics and disease and treatment variables were collected for each patient by physicians using a standard questionnaire, which was completed during face-to-face interviews, and hospital records. The symptoms at the time of data collection were recorded and graded using the Edmonton Symptom Assessment Scale (ESAS). The ESAS symptom scores were categorized by severity as follows: none $=0$; mild $=1-3$; moderate $=4-6$; and severe $=7-10$. The ESAS is a patient-reported validated tool for assessment of symptoms and its validity and reliability of ESAS for use in a Turkish population were established by Yesilbalkan et al. [3, 6]. The ESAS was supplemented with a question regarding whether or not the patient had difficulty initiating or maintaining sleep: "Do you frequently have difficulty in falling asleep at night or waking up frequently during the night or getting back to sleep after waking during the night?"

Data analysis (regarding the demographic characteristics, symptoms, and the potential predictors of symptoms) were performed using SPSS software (Version 13.01; SPSS Inc., Chicago, IL, USA). The $\chi^{2}$ test was used to compare categorical variables. The parametric Student $t$ test was used for comparing mean or median values of normally distributed data, and the nonparamet- 
Table 2. Distribution of symptoms according to severity and disease stage in patients with lung cancer

\begin{tabular}{|c|c|c|c|c|c|c|c|}
\hline \multirow[t]{2}{*}{ Symptoms } & \multirow[t]{2}{*}{ Stage } & \multicolumn{4}{|c|}{ Symptom severity } & \multirow[t]{2}{*}{ Total } & \multirow[t]{2}{*}{$p$} \\
\hline & & $\begin{array}{l}\text { no symptom } \\
n(\%)\end{array}$ & $\begin{array}{l}\text { mild } \\
n(\%)\end{array}$ & $\begin{array}{l}\text { moderate } \\
n(\%)\end{array}$ & $\begin{array}{l}\text { severe } \\
n(\%)\end{array}$ & & \\
\hline \multirow[t]{2}{*}{ Pain } & $1-2$ & $79(39.7)$ & $68(34.2)$ & $31(15.6)$ & $21(10.6)$ & \multirow[t]{2}{*}{1,186} & \multirow[t]{2}{*}{$<0.0001$} \\
\hline & $3-4$ & $327(33.1)$ & $246(24.9)$ & $216(21.9)$ & $198(20.1)$ & & \\
\hline \multirow[t]{2}{*}{ Tiredness } & $1-2$ & $48(24.1)$ & $69(34.7)$ & $51(25.6)$ & $31(15.6)$ & \multirow[t]{2}{*}{1,186} & \multirow[t]{2}{*}{$<0.0001$} \\
\hline & $3-4$ & $166(16.8)$ & $201(20.4)$ & $252(25.5)$ & $368(37.3)$ & & \\
\hline \multirow[t]{2}{*}{ Drowsiness } & $1-2$ & $90(45.2)$ & $66(33.2)$ & $26(13.1)$ & $17(8.5)$ & \multirow[t]{2}{*}{1,187} & \multirow[t]{2}{*}{$<0.0001$} \\
\hline & $3-4$ & $375(38.0)$ & $242(24.5)$ & $162(14.6)$ & $209(21.2)$ & & \\
\hline \multirow[t]{2}{*}{ Nausea } & $1-2$ & $115(57.5)$ & $48(24.0)$ & $30(15.0)$ & $7(3.5)$ & \multirow[t]{2}{*}{1,189} & \multirow[t]{2}{*}{0.018} \\
\hline & $3-4$ & $529(53.5)$ & $210(21.2)$ & $145(14.7)$ & $105(10.6)$ & & \\
\hline \multirow{2}{*}{ Lack of appetite } & $1-2$ & $95(47.0)$ & $50(24.8)$ & $38(18.8)$ & $19(9.4)$ & \multirow{2}{*}{1,191} & \multirow[t]{2}{*}{$<0.0001$} \\
\hline & $3-4$ & $319(32.3)$ & $177(17.9)$ & $199(20.1)$ & $294(29.7)$ & & \\
\hline \multirow[t]{2}{*}{ Shortness of breath } & $1-2$ & $51(25.6)$ & $78(39.2)$ & $48(24.1)$ & $22(11.1)$ & \multirow[t]{2}{*}{1,185} & \multirow[t]{2}{*}{$<0.0001$} \\
\hline & $3-4$ & $313(31.7)$ & $231(23.4)$ & $202(20.5)$ & $240(24.3)$ & & \\
\hline \multirow[t]{2}{*}{ Depression } & $1-2$ & $112(56.3)$ & $55(27.6)$ & $16(8.0)$ & $16(8.0)$ & \multirow[t]{2}{*}{1,185} & \multirow[t]{2}{*}{$<0.0001$} \\
\hline & $3-4$ & $468(47.5)$ & $200(20.3)$ & $163(16.5)$ & $155(15.7)$ & & \\
\hline \multirow[t]{2}{*}{ Anxiety } & $1-2$ & $98(49.2)$ & $55(27.6)$ & $26(13.1)$ & $20(10.1)$ & \multirow[t]{2}{*}{1,186} & \multirow[t]{2}{*}{0.002} \\
\hline & $3-4$ & $404(40.9)$ & $218(22.1)$ & $170(17.2)$ & $195(19.8)$ & & \\
\hline \multirow[t]{2}{*}{ Well-being } & $1-2$ & $71(45.3)$ & $63(37.3)$ & $39(6.7)$ & $25(10.7)$ & \multirow[t]{2}{*}{1,185} & \multirow[t]{2}{*}{$<0.0001$} \\
\hline & $3-4$ & $261(38.6)$ & $219(21.9)$ & $251(25.9)$ & $256(13.6)$ & & \\
\hline
\end{tabular}

ric Mann-Whitney U test was used to compare data that was not normally distributed. Factors that were potential predictors of symptoms (age, gender, body weight, disease stage, comorbidities, weight loss, histology [small-/non-small-cell lung cancer], metastasis, and time since diagnosis) were analyzed using logistic regression, as were symptoms that were the potential predictors of lack of well-being (pain, tiredness, drowsiness, nausea, lack of appetite, shortness of breath, depression, and anxiety). Multivariate logistic regression analysis was used as a stepwise descending method from predictive factors with a significance $\leq 0.05$ in the univariate analysis.

\section{Results}

A total of 1,245 lung cancer patients (1,104 [88.7\%] males; 141 [11.3\%] females) participated in the study. However, the number of patients included in analyses was variable because of some missing data. Of the 1,202 patients, 671 (55.8\%) had stage IV disease and the most frequent histologic type was squamous cell cancer (Table 1$)$. The mean age of the patients was $61.8 \pm 9.4$ years. The ESAS revealed that $1,085 / 1,216(89.2 \%)$ of the patients had more than one symptom, and tiredness $1,002 / 1,220(82.1 \%)$ was the most common symptom. There was a gradual increase in severity of symptoms based on the disease stages (Table 2). Patients with stages III and IV disease had more symptoms, and those with earlier stages had higher levels of well-being (Table 2). Of the patients, 590/1,218 (48.4\%) had difficulty initiating or maintaining sleep, and this was more common in the advanced stages (509/980 [51.9\%] vs. 63/200 [31.5\%], $p<$ $0.0001)$. Six hundred eleven (49.3\%) patients had unintended weight loss of at least $5 \mathrm{~kg}$, while $164(13.2 \%)$ patients gained weight during the treatment period. Weight loss was also more significant in the advanced stages (517/1,002 [51.6\%] vs. 75/199 [37.7\%], $p<0.001)$.

Logistic regression analysis indicated a clear association between demographic characteristics (age, gender, comorbidities, body weight, weight loss, disease stage, metastasis, and time since diagnosis) and symptom distress (Table 3). There was also a significant association between the symptom distress (except nausea) and wellbeing (Table 4).

\section{Palliation of Symptoms}

Dyspnea

Overall, $51.5 \%$ of the patients $(630 / 1,223)$ received treatment for dyspnea (Table 5). Of the 1,223 patients who received treatment for dyspnea, 78 (12.4\%) had resolution of dyspnea; while the remaining 549 (87.6\%) did not. On the other hand, 256 patients with mild/moderate dyspnea and 37 with severe dyspnea (total 293: 34.8\%) received no palliative therapy for their dyspnea.
Bülbül et al. 
Table 3. Multivariate logistic regression analysis of demographic parameters predicting symptoms in lung cancer

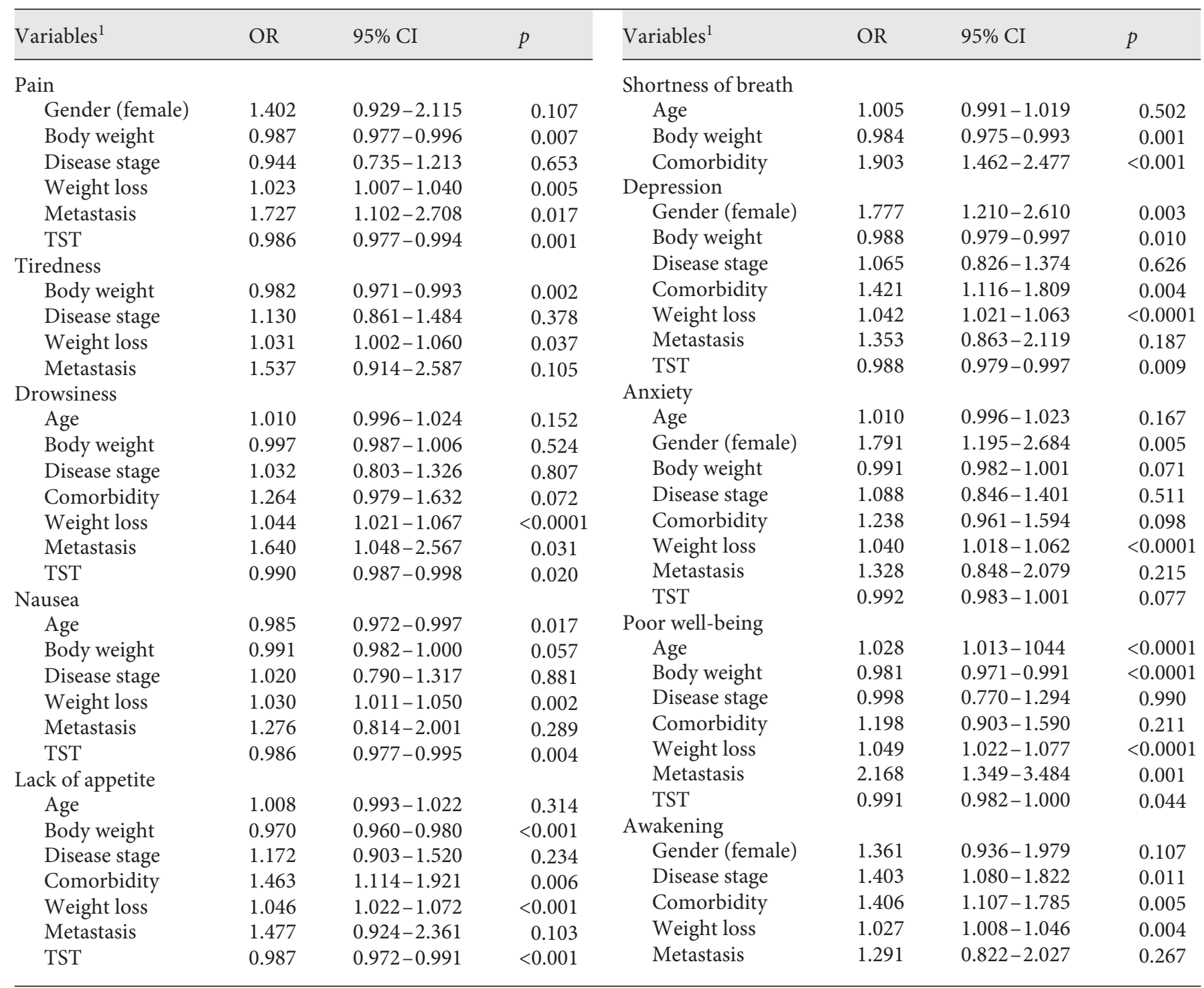

TST, time since diagnosis. ${ }^{1}$ Only variables derived from predictive factors with a significance $\leq 0.05$ in the univariate analysis were included.

Pain

Overall, of 1,229 patients, 804 (65.4\%) used analgesics (Table 5). Nonnarcotic and narcotic analgesic use alone or in combined forms were detected in $693(86.2 \%)$ and $320(39.8 \%)$ patients using analgesics $(n=804)$, respectively. Among the entire study population, these rates were $56.4 \%(693 / 1,229)$ and $26.0 \%(320 / 1,229)$, respectively. Only $173(21.7 \%)$ of the patients receiving analge- sics reported complete pain relief; 626 (78.3\%) patients reported continuing pain despite analgesic use. In contrast, $171(21.5 \%)$ patients reported no analgesic use despite having pain (147 with mild/moderate pain, 24 with severe pain). Two hundred ninety-one (43.9\%) patients had metastases to bone, and of these only 135 (39.6\%) were treated with bisphosphonates and 88 (30.2\%) were treated with palliative radiation. 
Table 4. Multivariate logistic regression analysis of symptoms predicting well-being in patients with lung cancer

\begin{tabular}{lccc}
\hline \multirow{2}{*}{ Symptoms } & \multicolumn{2}{l}{ Poor well-being } & \multirow{2}{*}{$p$} \\
\cline { 2 - 3 } & OR & $95 \%$ CI & \\
\hline Pain & 2.287 & $1.619-3.231$ & $<0.0001$ \\
Tiredness & 1.738 & $1.141-2.648$ & 0.010 \\
Drowsiness & 2.020 & $1.419-2.875$ & $<0.0001$ \\
Nausea & 0.975 & $0.646-1.472$ & 0.905 \\
Lack of appetite & 3.675 & $2.543-5.312$ & $<0.0001$ \\
Shortness of breath & 1.842 & $1.293-2.624$ & 0.001 \\
Depression & 2.848 & $1.723-4.708$ & $<0.0001$ \\
Anxiety & 4.281 & $2.717-6.745$ & $<0.0001$ \\
\hline
\end{tabular}

\section{Enteral/Parenteral Nutrition, Appetite Stimulant, and} Vitamin Use

Two hundred forty-two patients (out of 1,222;19.8\%) received enteral or parenteral nutrition; this was more prevalent in advanced stages than in those with stages I and II ( 21.4 vs. $10.0 \%$, respectively, $p<0.001)$. The reasons that patients used nutritional products were difficulty swallowing $(35 / 221,15.8 \%)$, cachexia $(85 / 221$, $38.5 \%)$, and other causes $(101 / 221,45.7 \%)$. The nutritional support was given via an oral route in 192/239 patients $(80.3 \%)$, via nasogastric tube in $10 / 239$ patients $(4.2 \%)$, via percutaneous endoscopic gastrostomy in $2 / 239$ patients $(0.8 \%)$, and via parenteral route in $35 / 239$ patients (14.6\%).

Of 1,224 patients, $132(10.8 \%)$ were using appetite stimulants, and use was more frequent in patients at advanced stages $(12.3$ vs. $4.5 \%, p<0.001)$. Of these, 93 (70.4\%) used megestrol acetate, 29 (22.0\%) used cyproheptadine, 2 (5.4\%) used a combination of these drugs, and $8(6.1 \%)$ used other medications. Overall, 81/1,041 (6.6\%) reported vitamin use, and 238/1,227 patients (19.4\%) reported the use of blood products including whole blood, erythrocyte suspension, plasma, etc.

Of the patients with appetite loss, 107/792 (13.4\%) were using appetite stimulants (79 megestrol acetate, 21 cyproheptadine, 9 a combination of drugs, and 5 other drugs). Twenty-five patients (18.9\%) using an appetite stimulant reported no appetite loss. Similarly, 77/602 $(12.8 \%)$ of the patients with weight loss were using an appetite stimulant (55 megestrol acetate, 17 cyproheptadine, 1 combination, 2 other). Again 38/454 (8.4\%) of the patients with no weight loss and $17 / 163(10.4 \%)$ of the patients with weight gain were using appetite stimulants.
Table 5. Palliative treatment options in patients with lung cancer

\begin{tabular}{|c|c|c|}
\hline & $\begin{array}{l}\text { Patients } \\
\text { receiving pallia- } \\
\text { tive treatment, } \\
n(\%)\end{array}$ & $\begin{array}{l}\text { All patients, } \\
n(\%)\end{array}$ \\
\hline \multicolumn{3}{|c|}{ Treatment of dyspnea $(51.5 \%, 630 / 1,223)$} \\
\hline Bronchodilator & $562 / 624(90.1)$ & $562 / 1217(46.2)$ \\
\hline Home oxygen & $177 / 619(28.6)$ & $177 / 1212(14.6)$ \\
\hline Nebulizer & $175 / 617(28.4)$ & $175 / 1210(14.5)$ \\
\hline Palliative radiotherapy & $55 / 613(9.0)$ & $55 / 1206(4.6)$ \\
\hline Thoracentesis & $43 / 613(7.0)$ & $43 / 1206(3.6)$ \\
\hline NIMV & $18 / 610(2.9)$ & $18 / 1210(1.5)$ \\
\hline $\begin{array}{l}\text { Endobronchial treatment/ } \\
\text { stenting }\end{array}$ & $12 / 614(2.0)$ & $12 / 1207(1.0)$ \\
\hline Pleurodesis & $11 / 613(1.8)$ & $11 / 1206(1.0)$ \\
\hline \multicolumn{3}{|c|}{ Analgesic use $(65.4 \%, 804 / 1,229)$} \\
\hline Paracetamol/ NSAID & $476 / 804(59.2)$ & $476 / 1224(38.9)$ \\
\hline Tramadol & $46 / 804(5.7)$ & $46 / 1215(3.8)$ \\
\hline Fentanyl & $36 / 804(4.5)$ & $36 / 1214(2.9)$ \\
\hline Morphine & $3 / 804(0.4)$ & $3 / 1211(0.2$ \\
\hline NSAIDs+tramadol & $73 / 804(9.1)$ & $73 / 1212(6.0)$ \\
\hline NSAIDs+fentanyl & $59 / 804(7.3)$ & $59 / 1211(4.9)$ \\
\hline NSAIDs+tramadol+fentanyl & 46/804 (5.7) & $46 / 1211(3.8)$ \\
\hline Other combinations & $62 / 804(7.7)$ & $62 / 1211(5.2)$ \\
\hline
\end{tabular}

NIMV, noninvasive mechanical ventilation; NSAID, nonsteroidal anti-inflammatory drug.

\section{Anxiolytic/Antidepressant Drugs and Sleeping Pills}

One hundred twenty-nine patients (129/1,222, 10.6\%) received anxiolytic/antidepressant treatment. Of these patients, $104(80.6 \%)$ had only depression or anxiety, while 25 (19.4\%) did not report having depression or anxiety. One hundred four patients $(104 / 1,221,8.5 \%)$ used sleeping pills and 84 of these patients $(80.8 \%)$ had complained of difficulty with sleep.

\section{Discussion}

In the current study, more than $85 \%$ of the lung cancer patients experienced multiple symptoms (ranging from mild to severe) regardless of their disease stage. Symptoms were more severe in the advanced stages than in stages I-II of the disease; the most common symptom was tiredness, followed by shortness of breath, loss of appetite, pain, drowsiness, anxiety, depression, and nausea. The finding that tiredness was the most common symptom of lung cancer was consistent with previous studies $[4,7]$. Equally, the findings that age, gender, comorbidities, body weight, weight loss, disease stage, me- 
tastasis, and time since diagnosis were independent predictors of lung cancer symptoms are similar to demographic features including age, gender, disease stage, treatment type, comorbidities, income, and weight loss that had been reported to be associated with symptom distress [8-10].

The finding in the current study that symptom distress was an independent predictor of well-being, except for nausea, was consistent with that of Lien et al. [11], who reported that the number of symptoms was negatively correlated with emotional distress and sense of well-being. Anxiety was the symptom that was most significantly associated with poor well-being. Smalbrugge et al. [12] also showed that presence of depression and/or anxiety has a clinically significant negative impact on well-being.

Our results indicate that there are a significant number of unmet needs reported by patients with lung cancer. Most patients in our study reported continuing symptoms, and a significant number of patients with dyspnea and pain reported that they were not receiving treatment. Similar to our results, some studies reported that lung cancer patients with high symptom scores were not undergoing any treatment $[7,9]$. Several studies have also shown that there is a high prevalence of uncontrolled symptoms in patients with advanced lung cancer [7, 13, 14].

Dyspnea is common in patients with lung cancer; it may develop due to malignant airway obstruction, lymphangitic spread, radiation or drug-induced pneumonitis, pleural effusion, accompanying chronic obstructive pulmonary disease, etc. Patient discomfort may be alleviated by radiotherapy, endobronchial treatment/stent placement, and thoracentesis, or pleurodesis for pleural effusion. In the present study, the rates of palliative radiotherapy, thoracentesis, endobronchial treatment/stent placement, and pleurodesis were 4.6, 3.6, 1.0, and $1.0 \%$, respectively; these results were comparable to those of the LUCEOR study [5]. However, home oxygen use and bronchodilator use in the current study were higher; we believe that those high percentages reflect the rate of comorbid chronic obstructive pulmonary disease patients, since $1 / 4$ to $1 / 2$ of lung cancer patients are reported to have chronic obstructive pulmonary disease [15].

In the present study, at least $50 \%$ of all patients were using nonnarcotic analgesics either alone or in combination with narcotic analgesics. Narcotic analgesic use (26.0\%) was similar to that in studies by Lester et al. [5] and Di Maio et al. [14] (19.2 and 23\%, respectively); however, nonnarcotic analgesic use in the current study (56.4\%) was higher than their results (30 and $13.7 \%$, respectively). Compared to our current data and that from previous studies, a study from Greece reported higher use of narcotic and nonnarcotic analgesics (80.6 and 64.2\%, respectively) in cancer patients [16]. In the current study, $30.2 \%$ of the patients underwent palliative radiotherapy for bone metastasis, which is similar to a report by Alexopoulos et al. [16]. Skeletal metastatic disease is the main cause of pain and the gold standard treatment for pain due to bone metastases is radiotherapy [17]. Bisphosphonates also play an important role in the treatment of bone metastasis; however, bisphosphonate use in the current study was lower than in the studies by Lester et al. [5] and Alexopoulos et al. [16].

The rates for nutritional support in the current study is in accordance with several studies reporting variable rates between 1.1 and $42.9 \%[5,18]$; however, the use of appetite stimulants (e.g., megestrol acetate and cyproheptadine) was lower than the percentages of patients with weight loss and appetite loss. Appetite stimulants may be effective alternatives in cancer patients suffering from anorexia/cachexia syndrome, but their effect on weight gain is controversial [19-22]. The use of blood products, including whole blood, erythrocyte, plasma, etc., was quite common in our patients. Erythrocyte and platelet use was reported as $9.1 \%$ in the LUCEOR study [5]. While $3.2 \%$ of the patients in that study reported using erythropoiesis-stimulating agents, they were not used at all in the current study.

The ratio of anxiety and depression in our study ( $50 \%)$ was comparable to previously reported data [23]. Similar to Salvo et al. [23] we found that female patients were more likely to report higher levels of anxiety and depression. Again, $48.4 \%$ of our patients had sleep problems, which is similar to Chen at al. [24] and Gooneratne et al. [25]. Sleep quality is associated with the distressing symptoms of lung cancer, and studies have shown a clear correlation between sleep quality and fatigue [24, 26], pain [27], and dyspnea and cough [28]. Despite the high rates of depression and anxiety in our patients, only $10.6 \%$ were using anxiolytic/antidepressant treatment. While approximately half of our patients had sleep disturbances, only $8.5 \%$ were using sleeping pills. In contrast to our current study, Farriols et al. [28] reported that $84 \%$ of patients were using benzodiazepines and $27.1 \%$ were using antidepressants, in a general cancer population.

The most important limitation of this study was that data collection was focused on the perceived burden of symptoms at a single time point. It is important to acknowledge that the results presented herein reflect only one point of a patient's life, and do not reflect symptoms during the entire disease duration. 


\section{Conclusion}

In this study the prevalence of symptoms was higher and most severe in patients in the advanced stages of the lung cancer than the other stages. Palliative treatment of symptoms was mostly inadequate, and large number of patients continued to suffer from uncontrolled symptoms and unmet needs. Because well-being was clearly associated with the distress from the symptoms, controlling these symptoms is important in patients with cancer. Hence, we recommend that patients undergo regular symptom assessment in order to achieve this, and treatment should be provided according to the published guidelines. Furthermore, both physician and patient education as well as more effective future therapeutic options are essential.

\section{References}

1 Kvale PA, Selecky PA, Prakash UB; American College of Chest Physicians: Palliative care in lung cancer: ACCP evidence-based clinical practice guidelines (2nd edition). Chest 2007; 132(3 suppl):368-403.

2 Thompson E, Sola I, Subirana M: Non-invasive interventions for improving well-being and quality of life in patients with lung cancer - a systematic review of the evidence. Lung Cancer 2005;50:163-176.

3 Bruera E, Kuehn N, Miller MJ, et al: The Edmonton Symptom Assessment System (ESAS): a simple method for the assessment of palliative care patients. J Palliat Care 1991; 7:6e9.

4 Li J, Girgis A: Supportive care needs: are patients with lung cancer a neglected population? Psychooncology 2006;15:509-516.

5 Lester JF, Agulnik J, Akerborg O, et al: What constitutes best supportive care in the treatment of advanced non-small cell lung cancer patients? Results from the Lung Cancer Economics and Outcomes Research (LUCEOR) study. Lung Cancer 2013;82:128-135.

6 Yesilbalkan ÖU, Özkütük N, Karadakovan A, et al: Validity and reliability of the Edmonton Symptom Assessment Scale in Turkish cancer patients. Turkish J Cancer 2008;38:62-67.

7 Seow H, Sussman J, Martelli-Reid L, et al: Do high symptom scores trigger clinical actions? An audit after implementing electronic symptom screening. J Oncol Pract 2012;8:e142e148.

8 Akin S, Can G, Aydiner A, et al: Quality of life, symptom experience and distress of lung cancer patients undergoing chemotherapy. Eur J Oncol Nurs 2010;14:400-409.

9 Oh EG: Symptom experience in Korean adults with lung cancer. J Pain Symptom Manage 2004;28:133-139.
10 Morita T, Kuriya M, Miyashita M, et al: Symptom burden and achievement of good death of elderly cancer patients. J Palliat Med 2014; 17:887-893.

11 Lien K, Zeng L, Zhang L, et al: Predictive factors for well-being in advanced cancer patients referred for palliative radiotherapy. Clin Oncol (R Coll Radiol) 2012;24:443-451.

12 Smalbrugge M, Pot AM, Jongenelis L, et al: The impact of depression and anxiety on well being, disability and use of health care services in nursing home patients. Int J Geriatr Psychiatry 2006;21:325-332.

13 Muers MF, Round CE: Palliation of symptoms in non-small cell lung cancer: a study by the Yorkshire Regional Cancer Organization thoracic group. Thorax 1993;48:339-343.

14 Di Maio M, Gridelli C, Gallo C, et al: Prevalence and management of pain in Italian patients with advanced non-small-cell lung cancer. Br J Cancer 2004;90:2288-2296.

15 Lee SJ, Lee J, Park YS, et al: Impact of chronic obstructive pulmonary disease on the mortality of patients with non-small-cell lung cancer. J Thorac Oncol 2014;9:812-817.

16 Alexopoulos EC, Koutsogiannou P, Moratis E, et al: Pain in cancer patients: the Greek experience. Eur J Oncol Nurs 2011;15:442-446.

17 Simmons CP, MacLeod N, Laird BJ: Clinical management of pain in advanced lung cancer. Clin Med Insights Oncol 2012;6:331-346.

18 Hebuterne X, Lemarie E, Michallet M, et al: Prevalence of malnutrition and current use of nutrition support in patients with cancer. JPEN J Parenter Enteral Nutr 2014;38:196204.

19 Davis MP: The emerging role of palliative medicine in the treatment of lung cancer patients. Cleve Clin J Med 2012;79(electronic suppl 1):eS51-eS55.
20 Ruiz Garcia V, Lopez-Briz E, Carbonell Sanchis R, et al: Megestrol acetate for treatment of anorexia-cachexia syndrome. Cochrane Database Syst Rev 2013;3:CD004310.

21 Vansteenkiste JF, Simons JP, Wouters EF, et al: Hormonal treatment in advanced nonsmall cell lung cancer: fact or fiction? Eur Respir J 1996;9:1707-1712.

22 Kardinal CG, Loprinzi CL, Schaid DJ, et al: A controlled trial of cyproheptadine in cancer patients with anorexia and/or cachexia. Cancer 1990;65:2657-2662.

23 Salvo N, Zeng L, Zhang L, et al: Frequency of reporting and predictive factors for anxiety and depression in patients with advanced cancer. Clin Oncol 2012;24:139-148.

24 Chen ML, Yu CT, Yang CH: Sleep disturbances and quality of life in lung cancer patients undergoing chemotherapy. Lung Cancer 2008;62:391-400.

25 Gooneratne NS, Dean GE, Rogers AE, et al: Sleep and quality of life in long-term lung cancer survivors. Lung Cancer 2007;58:403410 .

26 Akyuz RG, Ugur O, Elcigil A: Sleep quality in lung cancer patients. Asian Pacific J Cancer Prev 2013;14:2909-2913.

27 McMillan SC, Tofthagen C, Morgan MA: Relationships among pain, sleep disturbances, and depressive symptoms in outpatients from a comprehensive cancer center. Oncol Nurs Forum 2008;35:603-611.

28 Farriols C, Ferrandez O, Planas J, et al: Changes in the prescription of psychotropic drugs in the palliative care of advanced cancer patients over a seven-year period. J Pain Symptom Manage 2012;43:945-952. 